\title{
Confirmation of Association Between Autism and the Mitochondrial Aspartate/Glutamate Carrier SLC25A12 Gene on Chromosome 2q31
}

\author{
Ricardo Segurado, B.A., Ph.D. \\ Judith Conroy, B.A. \\ Eleanor Meally, B.A. \\ Michael Fitzgerald, M.B. B.Ch., M.D. \\ Michael Gill, M.B. B.Ch., M.D. \\ Louise Gallagher, M.B. B.Ch., Ph.D.
}

\begin{abstract}
Objective: Autism is a neurodevelopmental disorder with childhood onset and a known major genetic component. A recent study identified a highly significant association between autism and a two-single-nucleotide-polymorphism haplotype in the SLC25A12 gene, with a homozygote genotype relative risk between 2.4 and 4.8. The authors' goal was to investigate this
\end{abstract}

\begin{abstract}
association with autism in Irish affected child-parent trios because replication in an independent sample is essential in the validation of such potentially important findings.
\end{abstract}

Method: Markers rs2056202 and rs2292813 were genotyped in a total of 158 trios (442 individuals). The Transmission Disequilibrium Test was used to examine these markers for association with autism.

Results: In agreement with the recent study, the authors found significant association between autism and the $C$ alleles of both rs2056202 and rs2292813 as well as the two-marker haplotype.

Conclusions: These findings provide replication of the association between autism and SLC25A12.

(Am J Psychiatry 2005; 162:2182-2184)
A utism (number 209850 in the Online Mendelian Inheritance of Man, http://www.ncbi.nlm.nih.gov/entrez/ dispomim.cgi?id=300425) is a neurodevelopmental disorder of childhood onset, with an estimated prevalence of 5.5-20.0 in 10,000 (1), characterized by impairments in social interaction, communication, and behavior. Greater monozygotic than dizygotic concordance in twins $(60 \%-$ $90 \%$ versus $0 \%$ ) (2) and inflated sibling risk (3.0\%-4.5\%) indicate the importance of genetic factors in its etiology (3), with heritability estimates of $91 \%-93 \%$ (2), observations incompatible with simple Mendelian inheritance. Statistical modeling suggests that 3-15 loci may contribute to risk $(4,5)$ and that individual gene contributions are probably small.

Reports of linkage to 2q24-q33 (6-8) have implicated chromosome $2 q$ as potentially harboring a susceptibility locus. A recent study (9) screened nine candidate genes across 2 q31 for polymorphisms and explored genetic association in a sample of pedigrees including 671 autistic children. An association was detected with two single nucleotide polymorphisms (SNPs) in the third and sixteenth introns of the SLC25A12 gene: rs2056202 (I3-21A/G) and rs2292813 (I16+70A/G). In the present study we sought to confirm these findings in Irish affected parent-child trios.

\section{Method}

One hundred sixty-seven affected trios (174 affected individuals, including six affected sibships) were recruited, and probands were diagnosed according to Autism Diagnostic Interview-Revised (10) and Autism Diagnostic Observation Schedule-Generic (11) criteria for autism/autism spectrum disorder. Exclusion criteria included known medical causes of autism, IQ $<35$ (or mental age $<18$ months), chromosomal abnormalities, or fragile $\mathrm{X}$ syndrome. The Eastern Regional Health Authority Child and Adolescent Psychiatry Ethics Committee granted ethical approval.

Genomic DNA was extracted from blood or buccal swabs by standard methods and quantified. The Amplifluor method (Chemicon Corp., Temecula, Calif.) was used to genotype SNPs rs2056202 and rs2292813. The risk allele for both SNPs is represented by C on the sense strand, termed G by Ramoz et al. (9), who examined the reverse strand. 
Markers were examined for genotype errors and Mendelization inconsistencies with the PedCheck software program (12) in 158 affected trios. Allele and genotype frequencies from parents were calculated, tested for Hardy-Weinberg equilibrium, and examined for linkage disequilibrium $\left(D^{\prime}, r^{2}\right)$ by using the EMLD program (https://epi.mdanderson.org/ qhuang/Software/pub.htm). The markers and the two-marker haplotype were examined for association by using the Extended Transmission Disequilibrium Test program (13) and the TDTPHASE function of the UNPHASED package, which compensates for missing information and reconstructs haplotype phase where ambiguous, using an expectationmaximization algorithm (14).

\section{Results}

Genotypes at both markers were shown to follow the expected Hardy-Weinberg distribution. The markers were verified to be in linkage disequilibrium $\left(\mathrm{D}^{\prime}=1.0, \mathrm{r}^{2}=0.57\right)$. For markers rs2056202 and rs2292813, 64 and 50 families, respectively, had at least one affected child and one heterozygous parent. Association was detected at each marker individually with the Transmission Disequilibrium Test and, when examined as a haplotype, with TDTPHASE (Table 1).

The associated alleles were identical to those reported by Ramoz et al. (9) as showing biased transmission to affected children. Sample size and minor allele frequencies were insufficient for useful estimation of genotype relative risks.

\section{Discussion}

The association between autism and SLC25A12 was originally reported by Ramoz et al. (9) in 411 families, 197 of which had at least one affected child and one parent heterozygous for the marker. If the reported relative risk estimates in this association are accurate, we expect our study to have good power to detect such an association, if disease allele frequency is approximately equal to that of the risk $C$ alleles (0.8-0.9) (15). Our estimates of the effect size are of similar magnitude to those detected by Ramoz et al., suggesting that the risk factor may be the same in both studies.

The SLC25A12 gene comprises a 2,037-base-pair openreading frame, encoding the 678 amino acid mitochondrial aspartate/glutamate carrier, which resides in the mitochondrial inner membrane and is involved in the respiratory chain (16). It is difficult to hypothesize a model by which variation in this protein may contribute to the cause of autism because it is expressed predominantly in muscle and at lower levels in the brain (16). One could speculate that a defect in this gene could be compensated for by up-regulation or functional redundancy in some tissues, but that lack of compensatory mechanisms in tissues such as brain may lead to greater sensitivity to a slight deficiency in respiratory efficiency.

A functional role for the polymorphisms examined would be purely speculative because they are at opposite ends of the gene (approximately 68.3 kilobases [kb] apart), although they are in strong linkage disequilibrium with
TABLE 1. Results of Analysis of SLC25A12 Single Nucleotide Polymorphisms by Transmission Disequilibrium Test and Haplotype Analysis by TDTPHASE ${ }^{a}$ in 158 Irish Affected Child-Parent Trios

\begin{tabular}{lcccc}
\hline Item & Transmitted & $\begin{array}{c}\text { Not } \\
\text { Transmitted }\end{array}$ & $\begin{array}{c}\text { Odds } \\
\text { Ratio }\end{array}$ & $\mathrm{p}$ \\
\hline Transmission & & & & \\
$\quad$ Disequilibrium Test & & & & \\
rs2056202-C & 46 & 25 & 1.84 & $<0.02$ \\
rs2292813-C & 34 & 18 & 1.89 & $<0.04$ \\
Haplotype analysis & & & & \\
T-T & 21 & 39.2 & 1 & $<0.03^{\mathrm{C}}$ \\
T-C & 14.4 & 23.3 & 1.15 & \\
C-T & 0.0 & 0.0 & & \\
C-C & 288.6 & 261.5 & 2.06 & $<0.004$ \\
\hline
\end{tabular}

a From the Extended Transmission Disequilibrium Test program (13); the TDTPHASE function of the UNPHASED package compensates for missing information and reconstructs haplotype phase where ambiguous. $p$ values calculated by permutation (1,000 replicates).

${ }^{\mathrm{b}} \mathrm{T}$ - $\mathrm{T}$ was the reference haplotype.

${ }^{c}$ Global $p$ value.

each other. The possibility remains that another functional variant exists elsewhere, in linkage disequilibrium with the SNPs examined, possibly in an adjacent gene or regulatory site. Examination of the HapMap (http://www.hapmap. org) data across the gene and adjacent areas shows that strong linkage disequilibrium relationships between markers extend across the entire gene as well as the adjacent DNCI2, HAT1, and MAP1D genes in a linkage disequilibrium block of approximately $370 \mathrm{~kb}$, although these data are still relatively sparse. The exact location of any functional polymorphism responsible for susceptibility to autism, therefore, remains uncertain. However, given that we were testing a strong a priori hypothesis, we believe that the present study represents a confirmation of the association between autism and the $\mathrm{C}$ alleles at the rs2056202 and rs2292813 SNPs in the SLC25A12 gene.

Received Nov. 2, 2004; revision received Jan. 10, 2005; accepted Feb. 1, 2005. From the Department of Genetics, Trinity College Dublin; and the Department of Psychiatry, Trinity Centre for Health Sciences, Trinity College Dublin. Address correspondence and reprint requests to Dr. Segurado, Department of Genetics, Trinity College, Dublin 2, Ireland; rsegurdo@tcd.ie (e-mail).

Supported by grants H01041, H01071, and H01142 from the Health Research Board, Ireland; National Alliance for Autism Research grant DO2071; and Wellcome Trust grant W01014.

\section{References}

1. Chakrabarti S, Fombonne E: Pervasive developmental disorder in preschool children. JAMA 2001; 285:3093-3099

2. Bailey A, Le Couteur A, Gottesman I, Bolton P, Simonoff E, Yuzda E, Rutter M: Autism as a strongly genetic disorder: evidence from a British twin study. Psychol Med 1995; 25:63-77

3. Bolton P, Macdonald H, Pickles A, Rios P, Goode S, Crowson M, Bailey A, Rutter M: A case-control family history study of autism. J Child Psychol Psychiatry 1994; 35:877-900

4. Pickles A, Bolton P, Macdonald H, Bailey A, Le Couteur A, Sim $\mathrm{CH}$, Rutter M: Latent-class analysis of recurrence risks for complex phenotypes with selection and measurement error: a twin and family study of autism. Am J Hum Genet 1995; 57:717-726 
5. Risch N, Spiker D, Lotspeich L, Nouri N, Hinds D, Hallmayer J, Kalaydjieva L, McCague P, Dimiceli S, Pitts T, Nguyen L, Yang J, Harper C, Thorpe D, Vermeer S, Young H, Hebert J, Lin A, Ferguson J, Chiotti C, Wiese-Slater S, Rogers T, Salmon B, Nicholas P, Petersen PB, Pingree C, McMahon W, Wong DL, Cavalli-Sforza LL, Kraemer HC, Myers RM: A genomic screen of autism: evidence for a multilocus etiology. Am J Hum Genet 1999; 65: 493-507

6. Buxbaum JD, Silverman JM, Smith CJ, Kilifarski M, Reichert J, Hollander E, Lawlor BA, Fitzgerald M, Greenberg DA, Davis KL: Evidence for a susceptibility gene for autism on chromosome 2 and for genetic heterogeneity. Am J Hum Genet 2001; 68: 1514-1520

7. IMGSAC (International Molecular Genetic Study of Autism Consortium): A genomewide screen for autism: strong evidence for linkage to chromosomes 2q, 7q, and 16p. Am J Hum Genet 2001; 69:570-581

8. Shao Y, Wolpert CM, Raiford KL, Menold MM, Donnelly SL, Ravan SA, Bass MP, McClain C, von Wendt L, Vance JM, Abramson RH, Wright HH, Ashley-Koch A, Gilbert JR, DeLong RG, Cuccaro ML, Pericak-Vance MA: Genomic screen and follow-up analysis for autistic disorder. Am J Med Genet 2002; 114:99-105

9. Ramoz N, Reichert JG, Smith CJ, Silverman JM, Bespalova IN, Davis KL, Buxbaum JD: Linkage and association of the mito- chondrial aspartate/glutamate carrier SLC25A12 gene with autism. Am J Psychiatry 2004; 161:662-669

10. Lord C, Rutter M, Le Couteur A: Autism Diagnostic InterviewRevised: a revised version of a diagnostic interview for caregivers of individuals with possible pervasive developmental disorders. J Autism Dev Disord 1994; 24:659-685

11. Lord C, Risi S, Lambrecht L, Cook EH Jr, Leventhal BL, DiLavore PC, Pickles A, Rutter M: The Autism Diagnostic Observation Schedule-Generic: a standard measure of social and communication deficits associated with the spectrum of autism. J Autism Dev Disord 2000; 30:205-223

12. O'Connell JR, Weeks DE: PedCheck: a program for identification of genotype incompatibilities in linkage analysis. Am J Hum Genet 1998; 63:259-266

13. Sham PC, Curtis D: An extended transmission/disequilibrium test (TDT) for multi-allele marker loci. Ann Hum Genet 1995; 59(part 3):323-336

14. Dudbridge F: Pedigree disequilibrium tests for multilocus haplotypes. Genet Epidemiol 2003; 25:115-121

15. Risch N, Merikangas K: The future of genetic studies of complex human diseases. Science 1996; 273:1516-1517

16. Del Arco A, Satrústegui J: Molecular cloning of Aralar, a new member of the mitochondrial carrier superfamily that binds calcium and is present in human muscle and brain. J Biol Chem 1998; 273:23327-23334 